\title{
Study of Radiation Doses in Adult and Paediatric Patients Undergoing Computed Tomography Examination in Nigeria
}

\author{
Suleman Modu Ngaram ${ }^{1 *}$, Ibrahim Baba Mohammed ${ }^{2}$ \\ ${ }^{1}$ Department of Physics, Federal University Gashua, Gashua, Yobe, Nigeria \\ ${ }^{2}$ College of Health Technology Maiduguri, Maiduguri, Borno, Nigeria \\ Email: ^ngaramsuleiman@fugashua.edu.ng
}

How to cite this paper: Ngaram, S.M. and Mohammed, I.B. (2019) Study of Radiation Doses in Adult and Paediatric Patients Undergoing Computed Tomography Examination in Nigeria. Advances in Computed Tomography, 8, 37-45.

https://doi.org/10.4236/act.2019.83004

Received: August 20, 2019

Accepted: September 27, 2019

Published: September 30, 2019

Copyright $\odot 2019$ by author(s) and Scientific Research Publishing Inc. This work is licensed under the Creative Commons Attribution International License (CC BY 4.0).

http://creativecommons.org/licenses/by/4.0/

\begin{abstract}
The use of computed tomography (CT) has increased over the past decades and has resulted in a concurrent increase in medical exposure to ionizing radiation. Several recent studies have examined the link between medical radiation and the risk of cancer, especially in children. Results are presented in terms of the volumetric computed tomography dose index $\left(\mathrm{CTDI}_{\mathrm{vol}}\right)$ and dose length product (DLP) for head, chest and abdomen. The $75^{\text {th }}$ percentile of adult $\mathrm{CTDI}_{\mathrm{vol}}$ for head, chest and abdomen are $85 \mathrm{mGy}, 13.34 \mathrm{mGy}$ and $13.29 \mathrm{mGy}$ respectively and the corresponding DLP values $1437.47 \mathrm{mGy} \cdot \mathrm{cm}, 417.49$ and $656.02 \mathrm{mGy} \cdot \mathrm{cm}$. However, the paediatric head based on age group $0-1 \mathrm{yr}, 1-$ 5 yrs, 6 - 10 yrs and $11-15$ years are $28.18 \mathrm{mGy}, 32.12 \mathrm{mGy}, 32.13 \mathrm{mGy}$ and 28.20 $\mathrm{mGy}$ and corresponding DLP values $399.75 \mathrm{mGy} \cdot \mathrm{cm}, 514.38 \mathrm{mGy} \cdot \mathrm{cm}$, $578.42 \mathrm{mGy} \cdot \mathrm{cm}$ and $487.11 \mathrm{mGy} \cdot \mathrm{cm}$ respectively and for paediatric abdomen from 1 - 5 years to $11-15$ years are $3.98 \mathrm{mGy}, 4.26 \mathrm{mGy}$ and $5.92 \mathrm{mGy}$ and the corresponding DLP $99.36 \mathrm{mGy} \cdot \mathrm{cm}, 160.84$ and $235.85 \mathrm{mGy} \cdot \mathrm{cm}$. The finding

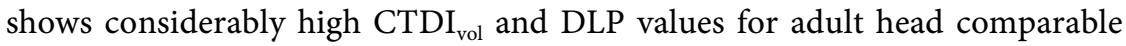
to the international standard thus optimization is required. Reduction in radiation doses for both adult and paediatric patients involve training of staff and optimize CT protocols.
\end{abstract}

\section{Keywords}

Radiation Doses, Computed Tomography, Pediatrics and Adults

\section{Introduction}

Computed tomography which is referred to as CT in medicine, CT is the highest ionizing radiation exposure that accounts for more than $30 \%$ ionizing radiation 
doses in the United States. However evidence shows that in 2010 about 80 million CT examinations were investigated as a result of outstanding imaging selection and high resolution that brings about details anatomical information [1]. This is suitable for the larger head, chest, abdomen/pelvis and other sensitive organs or soft tissue to be investigated. However in practice CT investigation or examination involves contrast agent pre and post to be administered to the patient in who irradiated volume increases by a factor of more than one [1]. CT uses $\mathrm{x}$-ray procedure to selectively obtain anatomical image details, where small dose of ionizing radiation is used in $\mathrm{x}$-ray technique. In medicine ionizing radiation is the process of depositing energy in form of heat to a given medium (matter) which changes the state and condition of the medium at such CT produces its images either for diagnostic or therapeutic purposes [2]. Since CT uses a very high ionizing radiation dose compared to that of $\mathrm{x}$-ray cannot be ignored without measuring the amount of radiation dose received by the patients undergoing CT examination [3]. Ever since the invention of computed tomography in 1972, CT had evolved in terms of high image quality for viewing physiological part of the patient body with a higher absorbed radiation dose that comes from it [4]. Though CT consists of scanner that revolves about a fixed point taking different two dimensional (2D) images at different location in different direction at different angles, however when these two dimensional images taken at different angles placed on a computer, the resultant image is three dimensional (3D) image that can reveal the presence of injuries and disease for either therapeutic or diagnostic purposes (Via Radiology, 2015). Furthermore in the last two decades CT could not take diagnostic or therapeutic images for thoracic within a shortest possible time but in recent years the same type of examination can be achieved within a second with a high resolution, this makes it more reliable and easy for physician to treat the patients very fast [5]. In recent years the image quality from CT has become more pronounced to a certain extent that the number of $\mathrm{CT}$ is on increase day by day, as the number of CT keeps increasing the amount of ionizing radiation dose also increases. However the increase of radiation dose is directly proportional to the risk associated with CT examination especially carcinogenic [6]. With the high risk involve in CT examination, pediatrics patients are at highest risk of cancer stimulation as a result of high ionizing radiation while pediatrics are radiosensitive compare to adult patients that have mature body composition and evidence shows that the rate at which death is occurring in pediatric due to cancer is as a result of exposure of head and abdomen to ionizing radiation from the CT in clinical practice of US, where CT examinations are carried out annually for more than six-hundred thousand on pediatrics patients [7]. With the various dose dependencies in mind, optimization techniques to reduce the dose of the patients, especially in regard to paediatric cases remains a popular focus of efforts (see for instance, [8]). The amount of radiation dose received by the patients during CT examinations which induce cancer risk varies from one CT center to another [9]. However these cancer risk and dose variation need to be optimized since patients and personnel are at risk to 
optimize and reduce the level of dose variation, the International Commission on Radiation Protection (ICRP) introduced the idea of diagnostic reference levels(DRLs) [10]. The effect of radiation doses from CT greatly depends upon choice of acquisition parameters, with potential for optimization. This research work investigates the analysis of radiation dose in adult and pediatric patients undergoing computed tomography examination.

\section{Materials and Methods}

The General Electric (GE) 16-slice (Figure 1) CT procedure for adult patients undergoing a routine CT scan is designed in chronological form of axial and helical mode for all type of examination, such as head, chest and abdomen. However, the tube current used for adult was in the range of $135 \mathrm{mAs}$ to $257 \mathrm{mAs}$ and for paediatric was $170 \mathrm{mAs}$ throughout with a fixed tube voltage of $120 \mathrm{KV}$ for the whole type of examination that was carried out during this research work with a pitch of $1.375 \mathrm{~mm}$. Single values for DLP and CTDI were noted and recorded.

\subsection{Sample Size}

In choosing the sample size for this study 30 patients were randomly selected each for head, chest and abdomen CT scan. However, 20 patients were selected on the minimum of twenty years each from 30 patients that were selected at random for the most three common CT examinations in adult. However, ten (10) paediatric patients were also selected each for head and abdomen as a result of limitation of the patients. Thus, Based on the recommendation guideline for sample selection made by the European commission which says a minimum of 10 samples shall be selected for each body part under examination [11]. However, the samples selected for paediatrics were grouped based on age (0 - 1 year, 1 5 years, 6 - 10 years and $11-15$ years). Thus, there was no patient for chest at the study centre as of the time I was collecting the data as well as $0-1$ year for

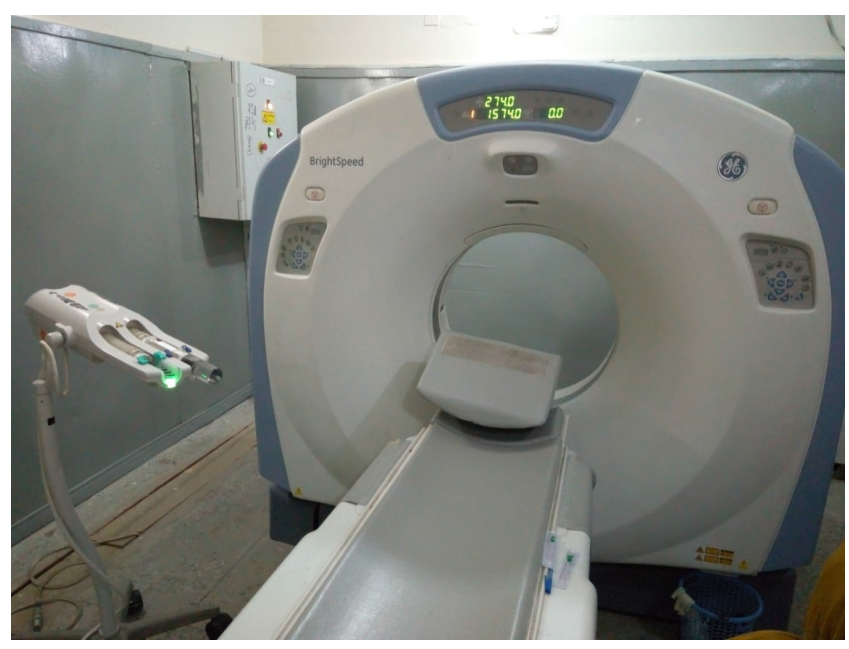

Figure 1. General Electric (GE) bright speed 16-slice CT scanner. 
abdomen CT scan. However, the total samples collected were 130 patients for final analysis in order to standardize the sample size.

\subsection{Inclusion Criteria}

- Both adult and paediatric patients were included.

- Only those came for a routine CT examination of head, chest and abdomen in both adult and paediatric patients were regard as valid samples.

- Only 17 years of age and above for adult patients were considered.

- Adult patients weighing $\pm 73 \mathrm{~kg}$ were considered for this work [1] [11] [12].

- CT scanner that was calibrated by the Nigerian Nuclear Regulatory Authority (NNRA) [1] [13].

\subsection{Exclusion Criteria}

- Adult Patients with below the age of 17 years were not included.

- Adult patients with weight below or above the specified limit mention above [12].

- A non-routine CT examination for both adult and paediatric.

\subsection{Dose Survey}

The Dose in CT was first described using the computed tomography dose index (CTDI). However, now the original definition has been changed following the technological improvements of CT. The CTDI is a basic concept to understand dose measurement in CT and is defined by

$$
\text { CTDI }=\frac{1}{n T} \int_{Z 1}^{Z 2} D(z) \mathrm{d} z(\mathrm{mGy})
$$

where: $D(z)$ as a function of $z$, is the outline of the absorbed dose along the $z$ axis, $n$ is the number of slices acquired in a single axial rotation, however the value of $n$ may be less or equal to the maximum number of channels available on the system (64 for a multislice CT detector with 64 rows). $T$ is the nominal thickness of the tomographic section or the Amplitude of the group of detectors used in the case of multislice CT ( $5 \mathrm{~mm}$ acquisition for a $4 \times 5 \mathrm{~mm}$ ) the CTDI can be measured using a $100 \mathrm{~mm}$ long pencil ionization chamber either in air $\left(\mathrm{CTDI}_{\text {air }}\right)$ or in a cylindrical polymethyl methacrylate (PMMA) phantom simulating the head (head $16 \mathrm{~cm}$ in diameter) and the body (body $32 \mathrm{~cm}$ in diameter) [10]. However the CTDI ${ }_{\text {air }}$ is the quality for each scanner and depends on tube current intensity, voltage, beam collimation, filtration and the geometric characteristics. Since dose sharing in the phantom is generally not uniform, the measurements are acquired in five different positions these position are in the center and at the four cardinal points, these resulted to introduction of the weighted CTDI $\left(\mathrm{CTDI}_{\mathrm{w}}\right)$ [10].

The weighted CTDI ${ }_{w}$, does not explain the involvement of pitch used during a spiral acquisition which can be written mathematically as 


$$
\mathrm{CTDIw}=\frac{1}{3} \mathrm{CTDI}_{100 \mathrm{c}}+\frac{2}{3} \mathrm{CTDI}_{100 \mathrm{p}}
$$

where $\mathrm{CTDI}_{100, \mathrm{c}}$ and $\mathrm{CTDI}_{100, \mathrm{p}}$ are measured at the center and at the periphery of the phantom, respectively, and the index 100 indicates that the CTDI was measured with a $100 \mathrm{~mm}$ long ionization chamber. However as a result of that, the volumetric CTDI was introduced to account for the pitch. The CTDI $_{\mathrm{vol}}$, is the CTDIw corrected for pitch [10].

$$
\mathrm{CTDI}_{\mathrm{vol}}=\frac{\mathrm{CTDIw}}{\text { Pitch }}
$$

However the effective $\mathrm{mAs}$ is $\mathrm{mAs}$ in one revolution per pitch, the value of the $\mathrm{mAs}$ can be read through the console of the computer depending on the type of company manufacture the machine, because some have no indication provisions on their console. Thus, the CTDI ${ }_{\mathrm{vol}}$ will not change with pitch; as such a single-slice cannot be acquired but the whole volume. Therefore, the scan length was considered to provide total exposure in complete CT examination.

DLP was introduced as dose descriptor which is referred to as dose length product. DLP is defined as the product of the CTDI ${ }_{\mathrm{vol}}$ multiplied by the irradiated scan length $(L)$. The DLP is measured in $\mathrm{mGy} \cdot \mathrm{cm}$.

$$
\mathrm{DLP}=\mathrm{CTDI}_{\mathrm{vol}} \times L
$$

The DLP is comprehensive dose descriptor that allows the risk to be evaluated through an estimation of the effective dose using the appropriate conversion factors defined by anatomical region. These conversion factors have been defined in a document of the European Commission [14] and updated after the release of ICRP 103 in 2007 to consider the weighting factors for the different tissues. Thus, the conversion factors for the body region are measured in $\mathrm{mSv} \mathrm{mGy}{ }^{-1} \cdot \mathrm{cm}^{-1}$. However, these values are: $0.0024,0.0053,0.020,0.016$ and 0.014 for skull, neck, chest, abdomen, and pelvis respectively [15].

\subsection{Dose Assessment}

A quantitative and retrospective research designed to determine the radiation dose absorbed by the adult and pediatric patients undergoing CT examination of head, chest and abdomen was adopted. However, the data obtained from the archive of the study center Federal Neuropsychiatric hospital Maiduguri were numerical values in which the quantitative design is suitable and was conducted retrospectively which ensured numerous valid and reliable data acquired [1] [16]. However, the study populations of this research work consist of adult and pediatric patients that attended CT examinations of head, chest and abdomen at the study center. The sheet was designed to extract patient measurement especially on the basis of comparative study such as demographic information, scan parameters and dose parameters.

Dose data such as CTDI ${ }_{\mathrm{vol}}$ and their corresponding DLP were extracted from patients' digital examination folders stored in the archive. However these dose values were read through the console of the display computer monitor and rec- 
orded on the data captured sheet for both adult and paediatric patients that have undergo the three common CT examinations (head, chest and abdomen) performed under the existing protocols in Federal Neuropsychiatric Hospital Maiduguri.

\section{Results and Discussion}

The exposure parameters were presented in (Table 1) below where, the adult tube voltage (KV) for head, chest and abdomen were fixed at $120 \mathrm{KV}$ (constant) but varies in tube current time for head (140 - 185) mAs, abdomen (135 - 257) $\mathrm{mAs}$ and $135 \mathrm{mAs}$ fixed for chest. However, the mean mAs for abdomen record the highest and lowest in chest (Table 1). Thus, the tube voltage for all paediatric age group in head were fixed at $120 \mathrm{KV}$ compared to adult patients and the corresponding paeditric $170 \mathrm{mAs}$ which is slightly less compared to adult head as you can see in Table 1 and Table 2.

However, the paediatric abdomen based on age group recorded $170 \mathrm{mAs}$ mean tube current time which is less than that of adult that mean value $207 \mathrm{mAs}$. But both the adult and paediatric patients recorded the same tube voltage of $120 \mathrm{KV}$ (Table 1 and Table 3). The mean CTDI $_{\text {vol }}$ (mGy) of adult head, chest and abdoment are $49.48 \mathrm{mGy}, 10.85 \mathrm{mGy}$ and $11.24 \mathrm{mGy}$ with their corresponding mean DLP (mGy.cm) values $749.69 \mathrm{mGy} \cdot \mathrm{cm}, 327.81 \mathrm{mGy} \cdot \mathrm{cm}$ and 517.15 $\mathrm{mGy} \cdot \mathrm{cm}$ (Table 4). However the mean $\mathrm{CTDI}_{\mathrm{vol}}(\mathrm{mGy})$ for paediatric head based on age group 0 - 1 year (19.39 mGy), 1 - 5 years (27.78 mGy), 6 - 10 years (30.95 $\mathrm{mGy}$ ) and $11-15$ years $(20.99 \mathrm{mGy})$ is less than that of adult head value (49.48 mGy) and related DLP values for adult $749.69 \mathrm{mGy} \cdot \mathrm{cm}$ higher than paediatric patients based on age group $(248.39,492.35,524.90$ and 366.38$) \mathrm{mGy} \cdot \mathrm{cm}$ (Table 4 and Table 5). However, the CTDI ${ }_{\mathrm{vol}}$ and DLP in paediatric increase as the age increases but decreased significantly towards the $11-15$ years (Table 5 and Table 6). Technical factors might be the contributors to high doses and dose variation Optimization and selection of parameter ought to reduce dose variation. This finding is of paramount importance in regards to the optimization

Table 1. Result of measured CT exposure parameters for organ dose measurement of adult patients.

\begin{tabular}{ccc}
\hline CT Examination & Tube Voltage $(\mathrm{KV})$ & mAs $($ Mean \pm SD) \\
\hline Head & 120 & $173.75 \pm 19.99$ \\
Chest & 120 & $135 \pm 00$ \\
Abdomen & 120 & $207 \pm 44.98$ \\
\hline
\end{tabular}

Table 2. Result of measured CT exposure parameters for organ dose measurement of pediatric head.

\begin{tabular}{ccccc}
\hline Age Group & $\mathbf{0}-\mathbf{1}$ Year & $\mathbf{1}-\mathbf{5}$ Years & $\mathbf{6}-\mathbf{1 0}$ Years & $\mathbf{1 1 - 1 5 \text { Years }}$ \\
\hline Tube Voltage $(\mathrm{KV})$ & 120 & 120 & 120 & 120 \\
mAs $($ Mean $\pm \mathrm{SD})$ & $170 \pm 00$ & $170 \pm 00$ & $170 \pm 00$ & $170 \pm 00$ \\
\hline
\end{tabular}


Table 3. Result of measured CT exposure parameters for organ dose measurement of pediatric abdomen.

\begin{tabular}{ccccc}
\hline Age Group & $\mathbf{0}-\mathbf{1}$ Year & $\mathbf{1}-\mathbf{5}$ Years & $\mathbf{6}-\mathbf{1 0}$ Years & $\mathbf{1 1}-\mathbf{1 5}$ Years \\
\hline Tube Voltage (KV) & 120 & 120 & 120 & 120 \\
mAs (Mean \pm SD) & $170 \pm 00$ & $170 \pm 00$ & $170 \pm 00$ & $170 \pm 00$ \\
\hline
\end{tabular}

Table 4. Measured CTDI ${ }_{\mathrm{vol}}(\mathrm{mGy})$ and DLP $(\mathrm{mGy} \cdot \mathrm{cm})$ dose values from the study center for adult patients.

\begin{tabular}{cccc}
\hline Center & Region & $\begin{array}{c}\text { CTDI }_{\text {vol }}(\mathrm{mGy}) \\
\text { Mean } \pm \text { SD }\end{array}$ & $\begin{array}{c}\text { DLP (mGy·cm }) \\
\text { Mean } \pm \text { SD }\end{array}$ \\
\hline \multirow{2}{*}{ FNPHM } & Head & $49.48 \pm 27.83$ & $749.69 \pm 490.90$ \\
& Chest & $10.85 \pm 4.05$ & $327.81 \pm 117.83$ \\
& Abdomen & $11.24 \pm 2.67$ & $517.15 \pm 153.86$ \\
\hline
\end{tabular}

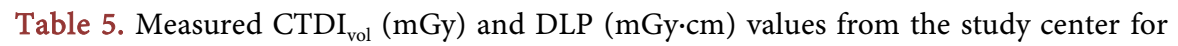
pediatric head.

\begin{tabular}{ccccc}
\hline Age Group & $0-1$ Year & $1-5$ Years & $6-10$ Years & $11-15$ Years \\
\hline $\begin{array}{c}\text { CTDI } \\
\text { Mean }(\mathrm{mGy})\end{array}$ & $19.39 \pm 8.64$ & $27.78 \pm 11.09$ & $30.95 \pm 1.90$ & $20.99 \pm 11.59$ \\
$\begin{array}{c}\text { DLP }(\mathrm{mGy} \cdot \mathrm{cm}) \\
\text { Mean } \pm \mathrm{SD}\end{array}$ & $248.39 \pm 148.73$ & $492.35 \pm 138.13$ & $524.90 \pm 86.38$ & $366.38 \pm 155.49$ \\
\hline
\end{tabular}

Table 6. Measured CTDI ${ }_{\mathrm{vol}}(\mathrm{mGy})$ and DLP $(\mathrm{mGy} \cdot \mathrm{cm})$ values from the study center for pediatric abdomen.

\begin{tabular}{ccccc}
\hline Age Group & 0 - 1 Year & $\mathbf{1}-\mathbf{5}$ Years & $\mathbf{6 - 1 0 \text { Years }}$ & 11 - 15 Years \\
\hline $\begin{array}{c}\mathrm{CTDI}_{\mathrm{vol}}(\mathrm{mGy}) \\
\text { Mean } \pm \mathrm{SD}\end{array}$ & $\mathrm{NA}$ & $3.29 \pm 0.79$ & $4.09 \pm 0.44$ & $4.82 \pm 0.91$ \\
$\begin{array}{c}\mathrm{DLP}(\mathrm{mGy} \cdot \mathrm{cm}) \\
\text { Mean } \pm \mathrm{SD}\end{array}$ & $\mathrm{NA}$ & $85.25 \pm 17.54$ & $148.34 \pm 25.84$ & $203.00 \pm 34.20$ \\
\hline
\end{tabular}

NA $=$ Not Available

process of our current practice. We find that lowering tube potential and utilizing a larger slice collimation are the most applicable methods for significantly reducing radiation dose to the patients without degrading the acquired image quality.

\section{Conclusion}

The CTDI ${ }_{\mathrm{vol}}$ and DLP dose values should not be exceeded when radiology departments operate under normal diagnostic and technical practice [11] [13]. However, the $75^{\text {th }}$ percentile of CTDI $\mathrm{vol}_{\text {vol }}$ and DLP dose values for routine chest and abdomen are comparable to those reported internationally in the literature; the CTDI ${ }_{\mathrm{vol}}$ and DLP dose values for head are considerably higher. Technical factors might be the contributors to high doses and dose variation optimization 
and selection of parameter ought to reduce dose variation. Paediatric patients with age group $11-15$ years in terms of CTDI $\mathrm{I}_{\mathrm{vol}}$ and DLP dose values are lower considerably compared to the 6 - 10 years age group. Retraining of staff should help reduce and optimize CT protocols for paediatric patients.

\section{Highlights}

- We study radiation doses received by both adult and paediatric patients from CT scan examination.

- Data obtained were compared with some international diagnostic reference levels.

- Doses from CT were influenced by CT parameter, scanning techniques and patient characteristics.

\section{Acknowledgements}

The authors wish to thank to the staff of Department of Radiology, Federal Neuropsychiatric Hospital Maiduguri, Borno State for providing us with information that enhance the completion of this study.

\section{Conflicts of Interest}

The authors declare no conflicts of interest regarding the publication of this paper.

\section{References}

[1] Sabiu, K.L. (2018) Assessment of Radiation Dose in Computed Tomography Examination of Adult in Three Diffrent Hospitals in Nigeria. Project Work.

[2] Ibrahim, U., Daniel, I.H., Ayaninola, O., Ibrahim, A., Hamza, A.M. and Umar, A.M. (2014) Determination of Entrance Skin Dose from Diagnostic X-Ray of Human Chest at Federal Medical Centre Keffi Nigeria. Science World Journal, 9, 12-14.

[3] Abdallah, S.E. (2010) Techniques and Radiation Dose in CT Examination of Adult Patients. Project Work Unpublished.

[4] European Commission (2014) Guideline on Quality Criteria for Computed Tomography.

[5] Edyean, S. (1998) Type Testing of CT Scanners Methods and Methodology for Assessing Imaging Performance and Dosimetry Report MDA/98/25. Medical Devices Agency, Landon.

[6] Ernest, U.E., Thomas, A., Judith, D.A., Owujekwe, C.E., Ali, A.M., Mohammed, A., et al. (2018) Diagnostic Reference Levels for Common Computed Tomography Examinations Results from the First Nigerian Nationwide Dose Survey. Journal of Radiological Protection, 38, 525-535. https://doi.org/10.1088/1361-6498/aaaaf8

[7] Brenner, D.J., Elliston, C.D., Hall, E.J. and Berdon, W.E. (2001) Estimated Risk of Radiation Induced Fatal Cancer from Pediatric CT. American Journal of Roentgenology, 176, 289-296. https://doi.org/10.2214/ajr.176.2.1760289

[8] Suliman, I.I., Abdallah, S.E., Ahmad, N.A., Galal, M.A. and Salih, I. (2011) Survey of Computed Tomography Technique and Radiation Dose in Sudanese Hospitals. European Journal of Radiology, 80, e544-e551. 
https://doi.org/10.1016/j.ejrad.2010.12.050

[9] Koller, C.J., Eatough, J.P. and Bettridge, A. (2003) Variation in Radiation Dose between the Same Model of Multislice CT Scanner at Different Hospitals. The British Journal of Radiology, 76, 798-802. https://doi.org/10.1259/bjr/33117342

[10] ICRP (2007) The Recommendation of International Commission on Radiological Protection. ICRP Publication 103. Annals of the ICRP, 37, 1-332.

[11] ICRP (1991) Publication 60. 1990 Recommendations of the International Commission on Radiation Protection. Annals of the ICRP, 21, 1-202.

[12] Garba, I., Engel-Hills, P., Davidson, F. and Tabari, A.M. (2015) Computed Tomography Dose Index for Head CT in Northern Nigeria. Radiation Protection Dosimetry, 165, 98-101. https://doi.org/10.1093/rpd/ncv188

[13] Adamu, M. (2018) Retrospective Assessment of Radiation Dose to Patients during Computed Tomography Scan in Some Selected Nigerian Hospitals. Project Work Unpublished, 11-44.

[14] Jessen, K.A., Panzer, W. and Shrimpton, P.C. (2000) The European Guidelines on Quality Criteria for Computed Tomography. Office for Official Publications of the European Communities, Luxembourg.

[15] Huda, W. and Magill, D. (2011) CT Effective Dose per Dose Length Product Using ICRP 103 Weighting Factors. Medical Physics, 38, 1261-1265.

https://doi.org/10.1118/1.3544350

[16] Punch, K.F. (2006) Developing Effective Research Proporsal. 